\title{
$\mathrm{CT}$ 의 선량 감소를 위한 sinogram 보간 기법
}

\author{
김 재 민*, 이 기 승
}

\section{A Method for Sinogram Interpolation for Reducing X-ray Dose}

\author{
Jae-Min Kim*, Ki-Seung Lee* \\ 요 약
}

본 논문에서는 전산화 단층촬영 시 스캔 시간의 단축 및 환자의 X-Ray 피폭량을 줄이기 위한 방법으로 샘플 링 빈도를 줄이고 적은 수의 view를 이용하여 단면 영상을 재구성하는 방법에 대해 연구하였다. 부족한 view로 인해 단면 영상에 발생하는 방사형의 직선형 왜곡(streak artifact) 를 억제하기 위하여 본 논문에서는 sinogram 보간기법을 적용하였다. 인접 view간 영상 특성(밝기, 그라디언트, 픽셀거리)을 기반으로 sinogram 픽셀 간의 매 칭을 수행하고 그 결과를 기반으로 변화패턴을 추적하여 sinogram을 보간하도록 하였다. Numerical 팬텀과 자체 제작된 팬텀을 이용하여 제안된 기법을 검증하였다. 선형 보간 기법에 비해 재구성된 단면영상의 디테일을 유지 하면서 왜곡이 감소하는 것이 관찰되었으며, PSNR면에서 최대 $5 \%$ 의 향상이 있는 것을 확인하였다.

Key Words : Interpolation, Sinogram, Computed Tomography(CT), Image Matching, X-ray dose, 보간법, 사이노그램, 전산화 단층촬영, 이미지 매칭, $X$ 선량

\section{ABSTRACT}

In this paper, a limited-view CT image reconstruction method was studied to reduce the scan times and the X-ray dose for the patients. To reduce streak artifacts which is caused by insufficient number of views, we introduce a sinogram interpolation method based on image matching. Image matching is achieved using the characteristics of the neighboring views including intensity, gradient and distance between the pixels. Interpolation is performed using the image matching results.. A numerical phantom and Al-acryl phantom were used for evaluating the effectiveness of the proposed interpolation method. The results showed that streak artifacts were reduced in the reconstructed images while the details of the images were preserved. Moreover, maximum $5 \%$ improvements in terms of PSNR were observed.

\section{I. 서 론}

$\mathrm{CT}$ (Computed Tomography)는 검출기가 물체 주 변을 회전하면서 X-선을 조사하며 해당 각도에서의 view를 얻고 역투영 기법을 통해 물체의 단면영상 을 얻는다. 이 때 임상 진단이 가능할 정도의 해상 도를 갖는 단면 영상을 재구성하기 위해서는 충분
한 양의 view가 필요하다. 이로 인해 환자가 받는 방사능 피폭량이 많아지고 스캔 시간이 길어진다는 문제가 있다 ${ }^{[1]}$.

피폭선량을 줄이기 위한 방법으로는 view의 수를 동일하게 유지하면서 X-선의 선량을 줄이는 방법과 선량은 기존 CT와 같이 유지하면서 view의 수를

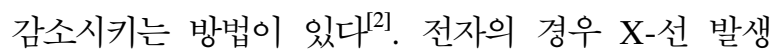

- 주저자 : 건국대학교 전자공학과 디지털신호처리 연구실, elfrious@konkuk.ac.kr, 준회원

* 건국대학교 전자공학과 디지털신호처리 연구실, kseung @konkuk.ac.kr, 정회원

논문번호 : KICS2012-02-105, 접수일자 : 2012년 2월 29일, 최종논문접수일자 : 2012년 6월 25일 
관의 전류·시간 단위 $(\mathrm{mAs})$ 를 낮추어 선량을 감소시 킨다. 이 경우 낮은 선량의 X-선이 밀도가 크거나 두꺼운 물질을 지나게 되면 검출기에 도달하는 X선 광자의 수가 줄어든다. 이로 인해 과다한 양자 잡음이 발생하여 재구성 된 단면영상에 왜곡을 발 생시킨다. 후처리를 통해 영상에 나타난 양자 잡음 을 감소시키는 기법들이 사용되지만 이들 기법은 잡음뿐만 아니라 필요한 정보까지 제거하는 문제가 있다 ${ }^{[3,4]}$.

조사 횟수를 줄이는 방식을 이용하게 되면 피폭 선량이 줄어들며, 한 장의 슬라이스 영상을 얻기 위 해 필요한 스캔 시간을 줄일 수 있다. 이 경우 영 상 재구성을 위한 충분한 view가 확보되지 않기 때 문에 방사형 직선형태의 왜곡이 발생한다 ${ }^{[1]}$. 이를 제거하기 위해서 부족한 view를 보간 (interpolation) 을 통해 추정하는데, 이때 사용되는 간단한 방법으 로는 선형보간법이 있다. 하지만 선형보간 기법은 sinogram에 대한 평균효과(averaging effect)로 인해 번짐현상(blurring effect)이 발생하고, 이러한 sinogram을 이용하여 재구성 한 영상에서는 단면을 구성하는 물질 중 감약계수의 차이가 큰 두 물질 사이의 경계면이 불분명하게 나타난다.

이러한 왜곡을 감소시키기 위해 인접한 두 개 view 사이의 view를 생성하는 방법으로 Galigekere 에 의해 제안된 단면의 재투사(reprojection)을 이용 한 보간 방식이 있다(Intermediate View Reprojecrion : IVR) $)^{[5]}$. 이 방식은 주어진 view를 이용하여 영상을 재구성한 뒤에 이 단면영상을 다 시 투사하는 방법을 이용하여 중간의 view를 얻는 기법이다. 이러한 기법은 고화질의 단면 영상을 얻 기 위해서 일정수 이상의 view가 반드시 필요하다 는 조건이 있고, 이미 왜곡이 존재하는 영상을 재투 사 하기 때문에 왜곡이 전파된다는 단점이 있다. 또 한 view의 개수가 일정 수준을 넘게 되면 왜곡이 다시 나타나는 문제가 보고되었다.

본 논문에서는 단면 영상의 화질을 개선하기 위 한 새로운 보간 기법을 제안하였다. 제안된 기법은 보간 시 방향성을 부여하기 위하여 두 개의 인접한 view에서 각 픽셀에 대한 이동패턴을 찾고 이로부 터 보간을 수행하는 방법을 적용하였다. 이동 패턴 의 추정에는 영상의 밝기, 그라디언트의 크기 및 방 향등으로 나타내어지는 픽셀의 특성을 이용하였다. 제안된 기법의 성능평가를 위해 numerical 팬텀 및 실제 제작된 팬텀을 이용하여 단면 영상을 얻고 기 존의 선형보간 기법과 객관적, 주관적인 비교를 수
행하였다.

본 논문의 구성은 다음과 같다. 1 장 서론에 이어 본 논문에서 제시하는 기법에 대한 자세한 내용을 2장 본문에서 기술하였으며, 3장의 실험에서는 본 기법의 유용성을 평가하기 위하여 numerical phantom과 aluminium/acryl phantom에 적용한 결 과를 다른 보간 기법들과 비교하였다. 마지막으로 4 장 결론으로 본 논문을 끝맺었다.

\section{II. 매칭 기반 보간 기법}

$\mathrm{CT}$ (Computed Tomography) 스캔을 하여 물체의 단면 영상을 얻기 위해서는 X-선 발생장치와 검출 기가 물체주변을 회전하며 여러 장의 이미지를 획 득하여야 한다. X-선이 물체를 지나 검출기에 투영 된 각각의 영상을 view라고하며 이들 view를 나열 한 것을 sinogram이라 한다. 이 sinogram에 재구성 알고리즘을 적용하여 단면의 영상을 얻는다. 재구성 알고리즘에는 역 매트릭스법, 반복 근사치 보정에 의한 재구성법, 역 투영법, 필터보정 역투영법 등이 있으며 본 연구에서는 필터보정 역투영법을 이용하 였다. 이는 각 방향에서 얻은 투영(ray)의 값을 역 으로 투사하여 단면의 영상을 추정하며, 역투영 시 에 발생하는 중심부의 번짐(blur)을 제거하기 위해 서 필터가 적용되었다.

고화질의 단면 영상을 재구성하기 위해서는 모든 방향에 대해 충분한 수의 view가 필요하다. view의 수가 부족하면 아래 그림 1 에서 보이는 것처럼 방 사형으로 뻗어나가는 직선형의 왜곡(streak artifact) 이 발생하게 된다.

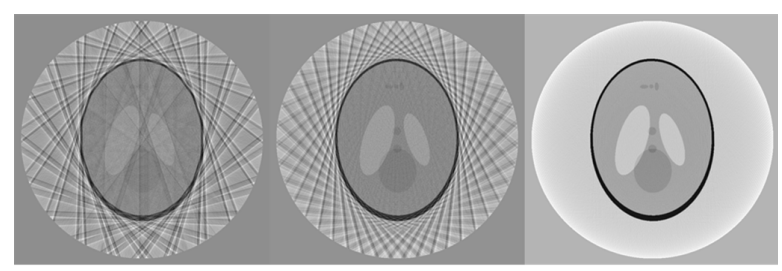

그림 1. view의 개수에 따른 재구성 영상 (좌로부터 20개, 45개 360 개 view를 사용)

Fig. 1. The tomographic images reconstructed from 20(left), 45(middle), and 360(right) views, respectively

환자에 대한 X-선 피폭량을 줄이기 위한 방법으 로 X-선의 조사 횟수를 줄이는 방식을 사용한다면, 조사되지 않은 각도에 해당하는 view에 대해 보간 법 들을 이용하여 view를 생성해 주어야 한다. 간 단한 선형 보간법(Linear interpolation)을 적용하는 경우에도 이러한 왜곡 현상은 눈에 띄게 감소하는 
것을 확인하였으나, 이 경우에 단면영상에 나타나는 물질의 경계부분이 명확하지 않게 되는 문제가 있 다. 이 문제는 그림 2에 나타난 것처럼 선형 보간 법의 특성상 각 view 간에 나타나는 형태적인 변화 가 무시되기 때문이다. X-선 발생기와 검출기가 물 체를 중심으로 회전하기 때문에 물체 내부의 형태 적인 특성은 sinogram상에서 정현파 모양을 따라 이동, 팽창, 축소하면서 나타난다. 따라서 영상의 정 확성을 유지하면서 아티팩트를 억제하기 위해서는 그림 3에 보인 것처럼 형태적 변화를 고려하여 중 간의 view를 생성해주어야 한다.
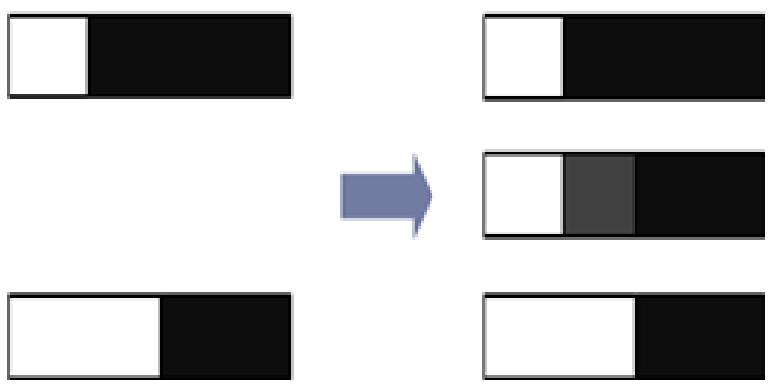

그림 2. 선형 보간법으로 중간 view를 생성한 경우

Fig. 2. In the case of linear interpolation
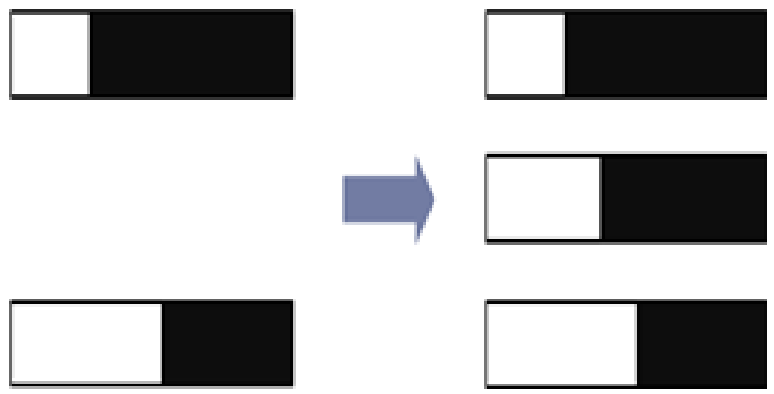

그림 3. 방향성을 고려하여 중간 view를 생성한 경우

Fig. 3. In the case of directional interpolation

위 그림 4 는 10 도 간격으로 회전하여 얻은 36 개 의 view를 갖는 sinogram 영상으로서, 인접한 두 개의 view를 보면 물체의 회전에 따른 변화는 경계 면이 좌우로 이동하거나 팽창 또는 축소하는 식으 로 나타나는 것을 관찰할 수 있다. 이러한 특성을 이용하면 변화하는 패턴을 추적할 수 있다. 이와 같 이 두 영상의 포인트간 유사성을 찾는 것을 Image Matching 또는 Image Registration 이라고 한다. A. Goshtasby등이 제안한 논문 ${ }^{[6]}$ 에서는 연속된 슬라이 스를 보간하여 물체의 체적 데이터를 얻는 이용하 였으나 본 논문에서는 sinogram에 적용하여 각 픽 셀간의 매칭을 수행하는데 적용하였다.

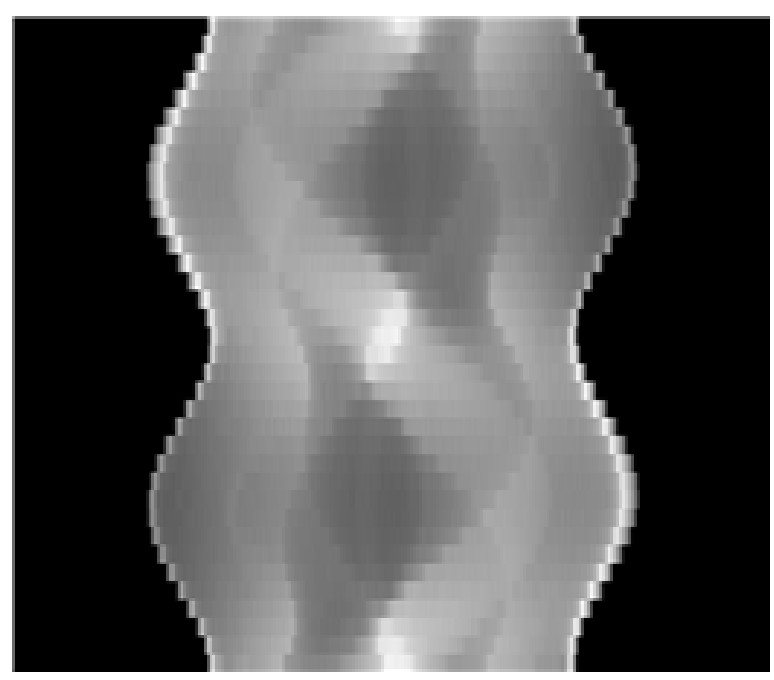

그림 4. 10도 간격으로 회전하며 얻은 sinogram Fig. 4. The sinogram acquired every 10 degree

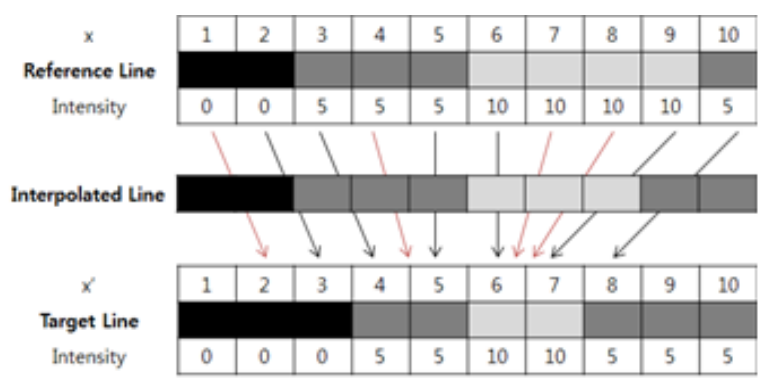

그림 5. 매칭 과정의 개요

Fig. 5. Matching procedure

그림 5는 매칭 과정을 간단히 보여준다. 이 방법 은 sinogram의 각 픽셀에 대해, 영상의 밝기, 픽셀 의 그라디언트 값, 픽셀간 거리를 이용하여 이들 값 의 차이가 가장 작게 나타나는 픽셀이 서로 매칭되 었다고 가정한다. 그림 5 에 보인 것과 같이 레퍼런 스 라인과 타겟 라인에서의 픽셀 위치를 각각 $\mathrm{x}$ 와 $\mathrm{x}$ 라고 할 때 아래의 식 (1)에서 나타내는 cost 함 수 $\mathrm{C}\left(\mathrm{x}, \mathrm{x}^{\prime}\right)$ 가 최소 값을 갖는 지점 $\mathrm{x}^{\prime}$ 를 $\mathrm{x}$ 가 이동 한 지점으로 간주한다.

$$
\begin{aligned}
C\left(x, x^{\prime}\right)= & u 1\left[I(x)-I\left(x^{\prime}\right)\right] i \\
& +u 2\left[D(x)-D^{\prime}\left(x^{\prime}\right)\right] j \\
& +u 3 \sqrt{\left(x-x^{\prime}\right)^{2}} k
\end{aligned}
$$

위의 식에서 $\mathrm{I}(\mathrm{x}), \mathrm{D}(\mathrm{x})$ 는 레퍼런스 라인 $\mathrm{x}$ 지점 의 밝기와 그라디언트를 의미하며, I'(x'), D'(x')는 타겟 라인 $\mathrm{x}$ '지점의 밝기과 그라이언트를 의미한다. $\mathrm{u} 1, \mathrm{u} 2, \mathrm{u} 3$ 는 지표(밝기, 그라이언트, 픽셀간 거리) 의 상대적 중요도를 나타내는 weighting factor이다. 
잘못된 매치를 줄이기 위해서는 매칭을 수행하기 전에 해당 지표들의 값이 0 255 사이에 존재하도 록 평준화가 행해져야 한다.

레퍼런스 라인 상의 $\mathrm{x}$ 지점이 타겟 이미지의 어 떤 지점로 이동하는지 찾기 위해서는 타겟 라인 상 에서 $\mathrm{x}$ 지점을 중심으로 하는 일정 크기의 윈도우를 설정하여 타겟 라인을 탐색하여야 한다. 이 때 밝기 값의 변화가 없는 구역, 즉 그라디언트 크기가 0 에 가까운 구역 내에서는 식 (1)의 $\mathrm{i}, \mathrm{j}$ 방향 성분의 크 기가 큰 차이를 보이지 않는다. 이로 인해 픽셀 간 거리가 가까운 지점을 일치점으로 간주하는 문제가 생긴다. 따라서 임계치 이상의 크기를 갖는 그라디 언트 값이 존재하는 지점을 대상으로 탐색을 진행 해야 이런 문제가 생기는 것을 방지할 수 있다. 탐 색의 결과로 레퍼런스 라인 상의 포인트 $\mathrm{x}$ 가 타겟 라인의 어떤 포인트로 이동하는지에 대한 맵을 얻 을 수 있다.

매칭 알고리즘을 이용한 sinogram 보간은 다음과 같은 단계로 행해진다.

단계1) 레퍼런스 라인과 타겟 라인의 각 픽셀에 대한 그라디언트를 구한다.

단계2) 그림 6과 같이 레퍼런스 라인의 그라디언 트 크기 $|\mathrm{D}(\mathrm{x})|$ 가 임계치 $\operatorname{tg}$ 이상인 지점 $\mathrm{x}$ 에 대해서 타겟 라인상의 매치되는 지점을 찾는다. 이를 통해 레퍼런스 라인 상의 포인트 $\mathrm{x}$ 가 타겟 라인의 어느 포인트로 이동하는지에 대한 transformation function : $\mathrm{f}(\mathrm{x})$ 를 얻게 된다.

2-1) 타겟 라인 상에서 $\mathrm{x}$ 를 중심으로 주어진 윈도우 크기 안에서 탐색을 하여 cost function $\mathrm{C}\left(\mathrm{x}, \mathrm{x}^{\prime}\right)$ 가 가장 작은 부분을 찾는다. 이 때 타겟 라인 상의 그라디언트 크기 $\left|\mathrm{D}^{\prime}\left(\mathrm{x}^{\prime}\right)\right|$ 가 임계치 $\mathrm{tg}$ 이상인 지점만을 대상으로 한다.

2-2) 그림 7과 같이 그라디언트 크기가 임계치 이하라서 매칭을 수행하지 않은 부분에 대해서는 주변 값을 이용하여 선형 보간을 한다.

단계 3) 레퍼런스 라인과 타겟 라인 사이에 존재 하는 새로운 view 라인을 생성한다. 레퍼런스 라인 의 $\mathrm{x}$ 지점과 타겟 라인 $\mathrm{x}^{\star}=\mathrm{f}(\mathrm{x})$ 인 지점 양측의 밝기 값 평균을 계산한다. 그림 8 에서 보이는 것과 같이 새로 생성되는 라인과 화살표가 만나는 지점에 이 평균 밝기 값을 채워 넣음으로서 새로운 라인을 생 성한다. 채워지지 않는 부분이 존재할 수 있으며 이
지점은 주변 값을 이용한 보간을 수행한다.

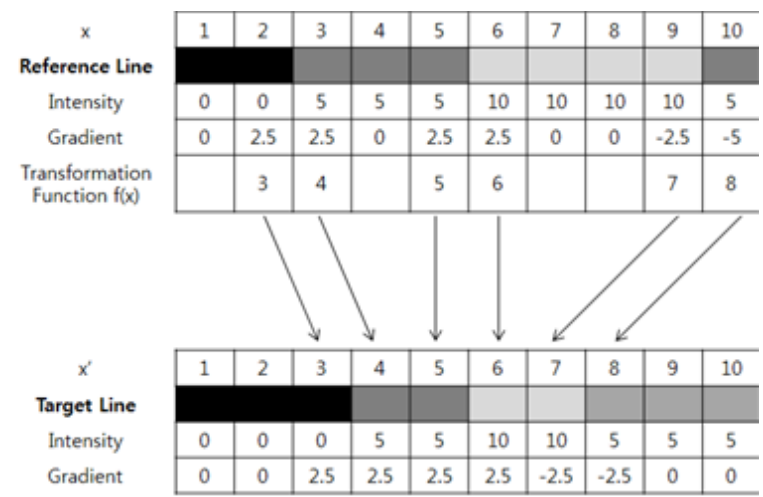

그림 6. 매칭 과정 중 2-1단계

Fig. 6. Matching Procedure : Step 2-1

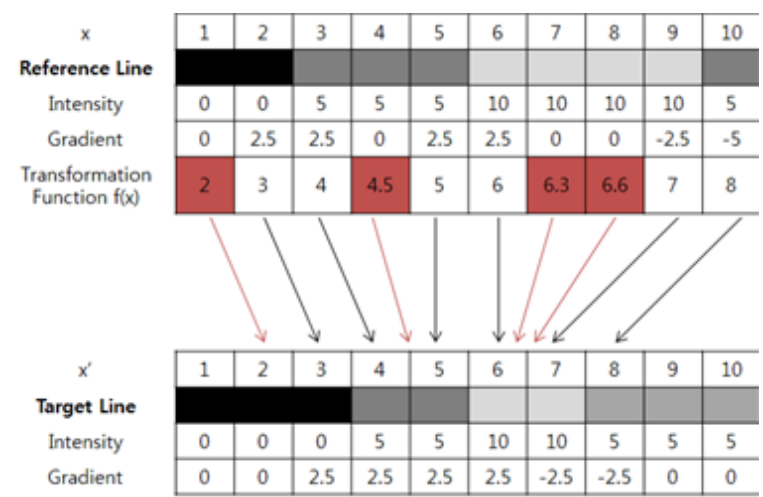

그림 7. 매칭 과정 중 2-2단계

Fig. 7. Matching Procedure : Step 2-2

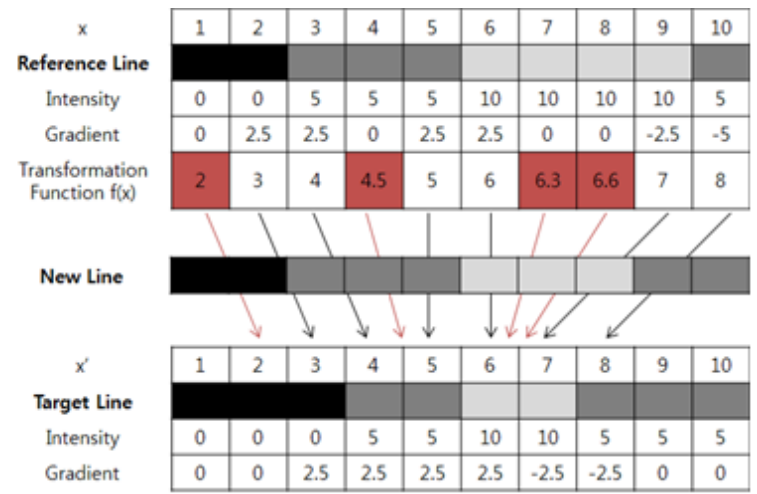

그림 8. 매칭 과정 중 3 단계

Fig. 8. Matching Procedure : Step 3

\section{III. 실험 및 결과}

실험에는 Shepp-Logan numerical 팬텀과 실험을 위해 제작한 팬텀을 이용하였다. 그림 9에 보이는 numerical 팬텀은 가로, 세로 각각 512 픽셀로 구 성되어있다. 소프트웨어적으로 fan beam 투과를 시 
뮬레이션하여 sinogram을 얻었다. 또한 실제로 얻어 진 X-선 데이터를 이용하여 단면 영상을 구성하기 위해 그림 10 과 같은 구조의 팬텀을 제작하여 실험 에 사용하였다. 팬텀은 알루미늄과 아크릴 및 인체 의 뼈를 구성하는 성분과 동일한 감쇠계수를 갖는 Hydroxyapatite(수산화인회석, resin과 섞어 고형화) 등으로 구성되었으며, 각각의 기둥은 다른 감쇠계수 를 갖도록 제작되었다.. 단면 영상의 구성 실험에서 는 그림 11 과 같이 턴테이블을 이용하여 물체를 회 전하여 각 방향의 view를 얻는 방식을 사용하였다. $\mathrm{X}$-선 발생장치는 최대 $150 \mathrm{kV} / 50 \mathrm{~kW}$ 용량을 갖는 회전-양극(Rotating Anode)방식의 X-선 튜브 (Toshiba E-7252X)가 사용되었으며, 검출기에는 $\mathrm{Gd} 2 \mathrm{O} 2 \mathrm{~S}$ 섬광기(Scintillator)와 amorphous silicon 포토다이오드로 구성된 평판형 검출기(Vatech, $\mathrm{Xmaru} 1210 \mathrm{PCB}$ )가 사용되었다. 평판형 검출기의 해상도는 가로, 세로 $2520 \times 2040$ 이며, 픽셀 간 간격 (pitch)는 $128 \mu \mathrm{m}$ 이다. 실험 환경 중 $\mathrm{X}$-선의 시작점 에서 검출기까지의 거리(L)는 $1152 \mathrm{~mm}$ 이고, 시작점 과 회전축 중심 사이의 거리(D)는 $768 \mathrm{~mm}$ 이다. 샘 플을 얻기 전에, 튜브에서 발생되는 $\mathrm{X}$-선의 불균일 과 평판에 위치한 센서들의 부분별 감도 차이를 보 정하기 위한 calibration 및 불량 픽셀을 제거하기 위한 Bad Pixel Removal 과정을 수행하였다.

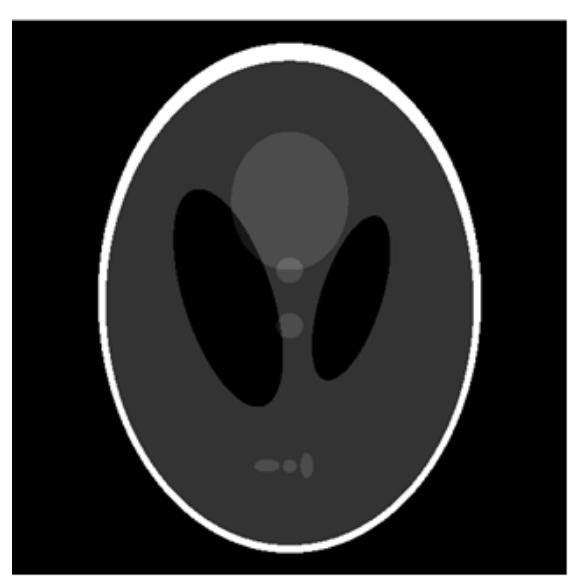

그림 9. Shepp-Logan 팬텀 이미지

Fig. 9. Shepp-Logan numerical phantom image

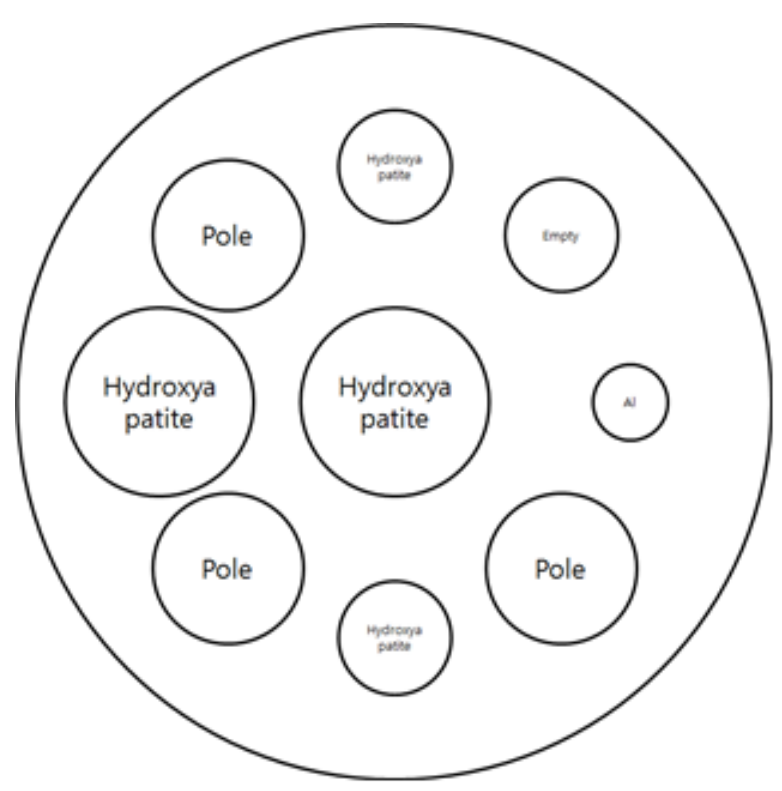

그림 10. 알루미늄/아크릴/수산화인회석 팬텀의 구조

Fig. 10. The phantom used in experiments, which is composed of aluminium, acryl and hydroxyapatite

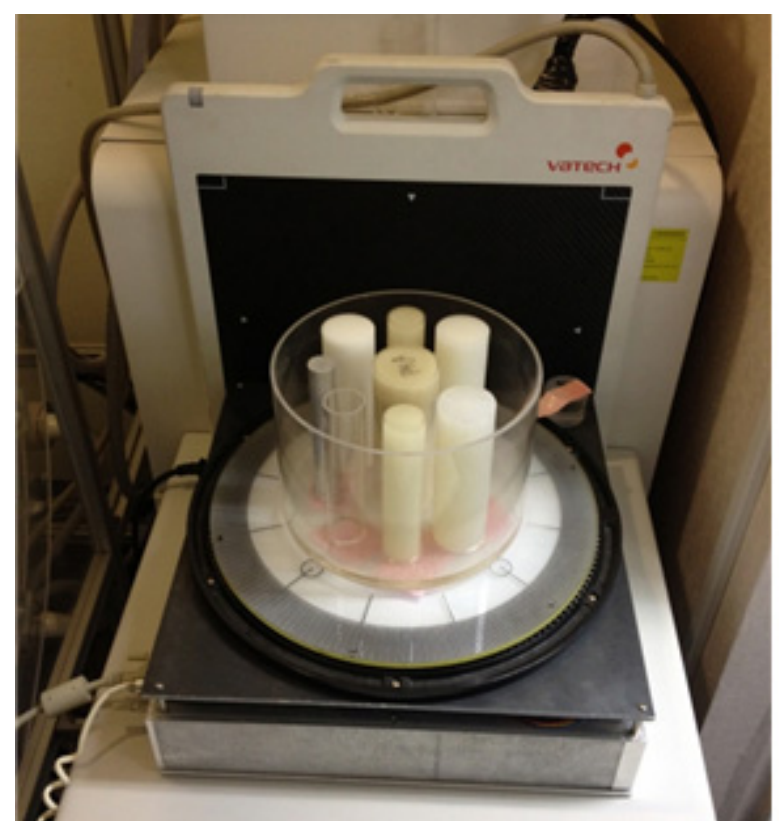

그림 11. 팬텀과 턴테이블, 검출기의 배치

Fig. 11. The photograph of detector side of the experimental CT system

팬텀의 촬영은 관전압 $75 \mathrm{kVp}$, 관전류 $40 \mathrm{~mA}$ 의 설정으로 이뤄졌으며, $2 \mathrm{mAs}$ (전류.시간)의 선량을 이용하여 매 view를 획득하였다. beam hardening현 상 및 노이즈를 억제하기 위해서 $6 \mathrm{~mm}$ 두께의 알루 미늄 필터를 X-선 발생 장치의 콜리메이터에 추가 하여 사용했다. 화질 비교의 기준으로 삼은 것은 
360 개의 view를 이용하여 재구성한 단면 이미지이 다. view의 수를 변화시키며 각각 보간법을 적용하 여 재구성한 결과들을 아래 식에 주어진 PSNR(Peak Signal to Noise Ratio) 값을 이용하여 비교하였다.

$$
\begin{gathered}
P S N R=20 \log _{10}\left(\frac{i \operatorname{Max}}{\mathrm{RMSE}}\right) \\
R M S E=\sqrt{\frac{1}{N M} \sum_{i=1}^{N} \sum_{j=1}^{M}[f(i, j)-\hat{f}(i, j)]^{2}}
\end{gathered}
$$

이때 $f(x, y)$ 와 $\hat{f}(x, y)$ 는 비교할 이미지이며, $\mathrm{N}$ 과 $\mathrm{M}$ 은 이미지의 가로, 세로 픽셀수이다. $i M a x$ 는 $f(x, y)$ 와 $\hat{f}(x, y)$ 가 가지는 최대 밝기 값이다.

결과비교는 다음과 같은 방식으로 진행하였다.

1) 1 도 간격으로 회전하며 view를 얻어서 sinogram 구성 (360개의 view로 이뤄짐)

2) 1)의 sinogram을 이용하여 재구성한 영상을 레퍼런스 영상으로 이용함

3) view의 개수를 다르게 하여 아래의 보간 방식 을 적용 후 재구성

3-1) 보간법을 사용하지 않은 경우

3-2) 선형 보간법을 사용한 경우

3-3) 본 논문에서 제시한 보간법을 사용한 경 우

4) 재구성 된 영상들과 레퍼런스 영상의 PSNR 을 구하여 비교함

\subsection{Shepp-Logan Numerical Phantom에 보간 법을 적용한 경우}

Shepp-Logan 팬텀의 sinogram과 재구성한 이미 지는 아래 그림 12 와 같다. 오른쪽의 재구성 영상 을 레퍼런스 영상으로 사용한다.

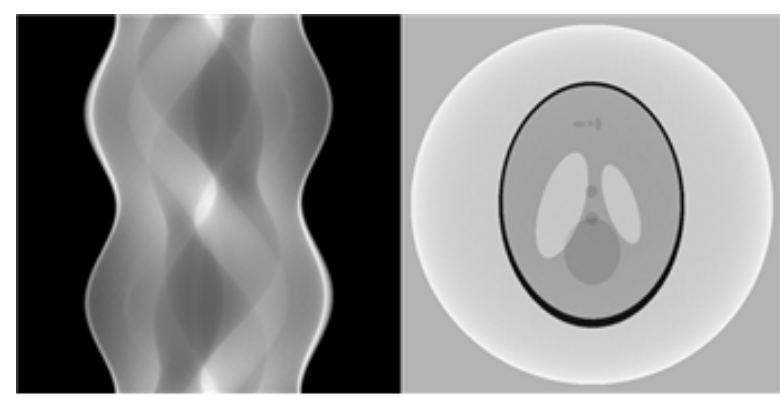

그림 12. Shepp-Logan 팬텀의 sinogram(좌)과 재구성 영상 (우)

Fig. 12. Sinogram of Shepp-Logan phantom(left) and reconstructed image(right)

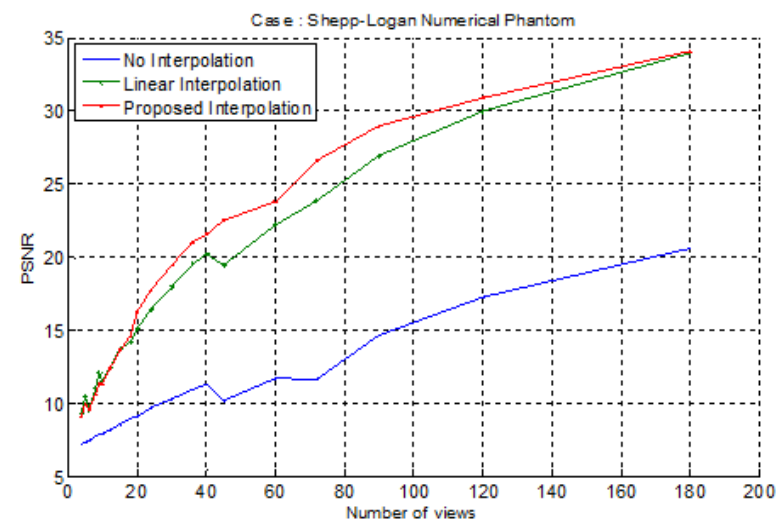

그림 13. Numerical 팬텀의 view 개수에 따른 PSNR 곡선

Fig. 13. The PSNR plots of the various number of views, for numerical phantom

시뮬레이션을 이용해 sinogram을 얻는 경우에는 $\mathrm{X}$-선의 산란이나 검출기 노이즈 등의 영향이 나타 나지 않기 때문에 이미지 매칭 과정의 정확도가 매 우 높다. 정확한 매칭 결과를 기반으로 이뤄지는 보 간 기법은 효과적이다. 그림 13 은 각 방법에 대한 view의 개수와 PSNR과의 관계이다. sinogram 단계 에서 매칭이 효과적으로 이루어지기 때문에 거의 모든 view개수에 대해 본 논문에서 제시한 보간 기 법의 PSNR값이 우수하게 나타난다. 실제 재구성 영상은 그림 14 와 같다. 보간을 사용하지 않은 (a) 와 비교하면 보간을 사용한 (b)와 (c)의 영상에서 방사형 왜곡이 제거된 것을 확인할 수 있다. 그림 15 는 선형보간법과 제안하는 보간법을 비교하기 위 해 부분 확대한 영상이다. 이 경우에 선형보간법을 사용한 왼쪽 영상에 비해, 제안된 보간 기법을 사용 한 오른쪽의 영상의 물질 경계면이 좀 더 명확하게 보이는 것을 확인할 수 있다. 이는 그림 16 에서 보 이는 것과 같이 제안된 기법을 사용하면 형태적인 이동패턴을 고려하여 보간이 이뤄지기 때문이다. 


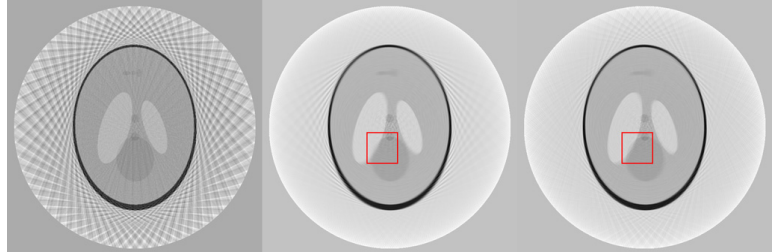

(a)

(c)
그림 14. 60 개의 view를 이용하여 재구성한 영상 (a) 보간 법 미사용 (b) 선형보간법 사용 (c) 제안된 보간법 사용 Fig. 14. The reconstructed image using (a) no interpolation (b) linear interpolation (c) proposed interpolation in case of 60 views

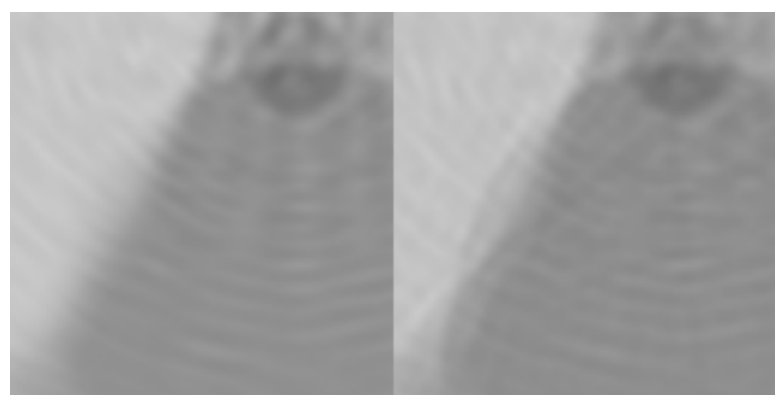

그림 15. 60 개의 view를 이용하여 재구성한 영상의 부분확 대 (a) 선형 보간법 사용 (b)제안된 보간법 사용

Fig. 15. The magnified view of reconstructed image using (a) linear interpolation (b) proposed interpolation in case of 60 views

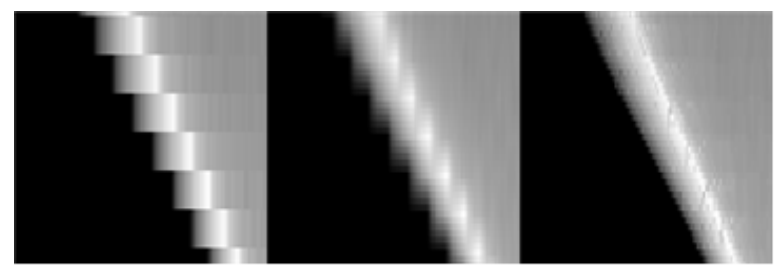

그림 16. 보간된 sinogram의 부분 확대 모습 (a) 보간법 미 사용 (b) 선형보간법 이용 (c) 제안된 보간법 이용

Fig 16. The magnified view of sinograms using (a) no interpolation (b) linear interpolation (c) proposed interpolation

\subsection{Aluminium/Acryl Phantom에 보간법을 적 용한 경우}

실험에 쓰인 Aluminium/Acryl 팬텀의 sinogram 과 재구성한 이미지는 아래의 그림과 같다. 오른쪽 의 재구성 영상을 레퍼런스 영상으로 사용한다.
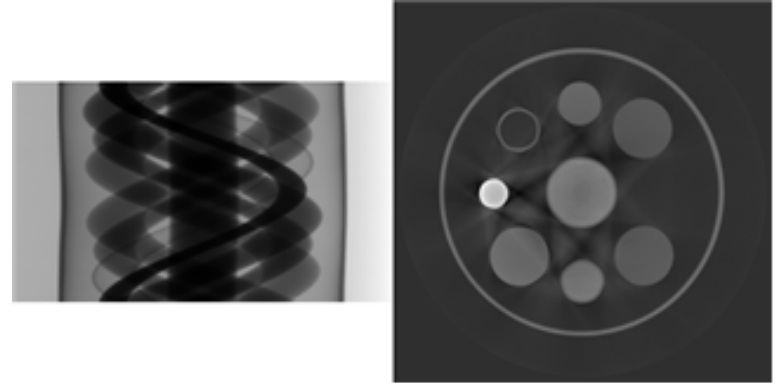

그림 17. Aluminium/Acryl 팬텀의 sinogram(좌)과 재구성 영상(우)

Fig. 17. Sinogram of Al/Acryl phantom(left) and reconstructed image(right)

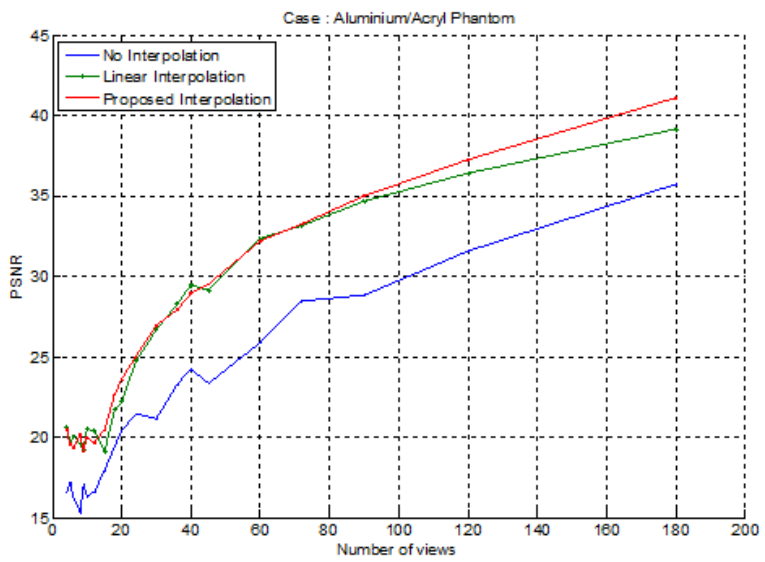

그림 18. Al/Acryl 팬텀의 view 개수에 따른 PSNR 곡선 Fig. 18. The PSNR plots of the various number of views, for $\mathrm{Al} /$ Acryl phantom

실제 $\mathrm{X}$-선 촬영 시에는 $\mathrm{X}$-선의 산란, 검출기에서 발생하는 에러, 기계적인 동작 오차 등이 데이터에 영향을 미친다. numerical 팬텀의 경우와 비교했을 때 영상에 나타난 이러한 잡음은 매칭의 정확성을 떨어뜨린다. 매칭 시에 그라디언트 값의 비중을 높 게 두고 탐색하는 경우에 좋은 결과가 나오는 것을 확인하였으나, 이는 실험 환경에 따라 달라질 수 있 다. 그림 18 의 결과를 보면 view의 수가 100 개 미 만인 경우 선형보간법에 비해 영상의 질이 떨어지 지만, view의 수가 100 개 이상이 되면 결과 영상의 화질이 향상되는 것을 관찰할 수 있다. 의료영상 분 야에 실제적으로 사용되는 기기들의 경우 720 개 또 는 그 이상의 view를 이용하여 재구성 하는 것이 일반적이다 ${ }^{[7,8]}$. 이 기법이 선형보간법보다 나은 결 과를 얻기 위해 필요한 최소 view의 개수( 100 개)는 실제 사용되는 view 개수의 $1 / 6 \sim 1 / 7$ 수준이므로 실제 적용에는 문제가 되지 않을 것으로 판단된다. 보다 많은 수의 view를 이용할수록 선형 보간법와 의 차이는 점차 커지는 것을 알 수 있다. sinogram 


\section{보간법을 적용한 결과를 그림 19-21에 제시하였다.}

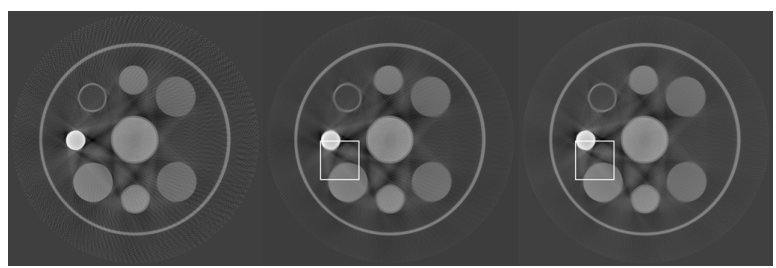

그림 19. 180 개의 view를 이용하여 재구성 한 영상 (a) 보 간법 미사용 (b) 선형보간법 사용 (c) 제안된 보간법 사용 Fig. 19. The reconstructed image using (a) no interpolation (b) linear interpolation (c) proposed interpolation in case of 180 views

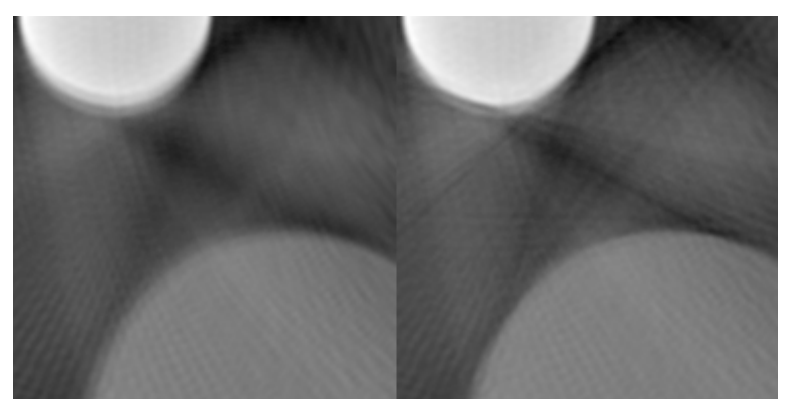

그림 20. 180 개의 view를 이용해서 재구성한 영상의 부분 확대 (a) 선형보간법 사용 시 (b) 제안한 보간법 사용 시 Fig. 20. The magnified view of reconstructed image using (a) linear interpolation (b) proposed interpolation in case of 180 views

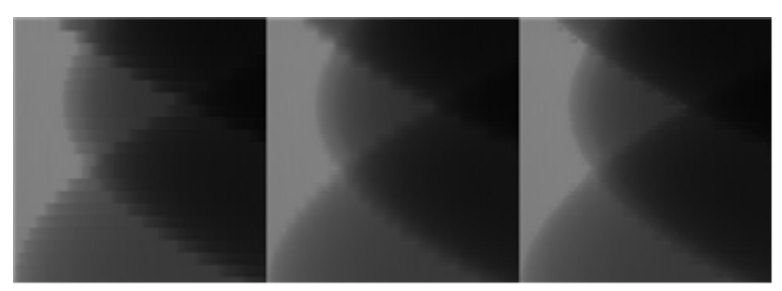

(a)

(b)

(c)

그림 21. 보간된 sinogram의 부분 확대 모습 (a) 보간법 미 사용 (b) 선형보간법 사용 (c) 제안한 보간법 사용

Fig. 21. The magnified view of sinograms using (a) no interpolation (b) linear interpolation (c) proposed interpolation

그림 19는 보간법을 사용하지 않은 경우와 각 보 간법을 적용한 결과를 보여준다. Numerical 팬텀의 경우와 비슷하게 두 보간법 모두에서 방사형 직선 왜곡은 만족할 수준으로 억제되는 것을 볼 수 있다. 그림 20 에서 단면에서 물질 간 경계면의 명확도가 어느 정도 유지되는지 비교하기 위해서 부분 확대 모습을 확인하였다. 제안한 보간 기법을 사용한 오 른쪽의 영상에서 경계면이 좀 더 명확하게 나타나 며, 특히 아래쪽의 아크릴 기둥 경계면에서 두드러
지는 차이를 보인다. 그림 21은 sinogram의 일부분 을 확대한 영상이다. 선형보간법을 사용한 (b)영상 에서는 계단현상이 보이지만, 제안된 보간법을 사용 한 (c)영상에서는 계단현상을 일정 수준 억제하여 평탄하게 만드는 것을 확인할 수 있다.

view의 개수가 적은 경우에 보간법의 효율이 좋 지 않은 이유는 매칭 포인트 간의 연결은 직선으로 행해지기 때문이다. 이상적인 sinogram에서 물질의 경계면은 회전 각도에 따라 정현파의 궤적을 따라 움직인다. 그림 22의 (a)에 보이는 것과 같이 가까 운 간격으로 샘플링이 이뤄진 경우 각 view 사이의 매칭은 정현파의 미소단위, 즉 기울기와 가깝게 나 타나지만, (b)와 같이 큰 간격으로 샘플링이 되는 경우 매칭과 실제 sinogram에 나타나는 정현파 사 이에는 오차가 크게 나타나게 되어, 결과적으로 재 구성 영상의 화질에 영향을 미치게 된다.

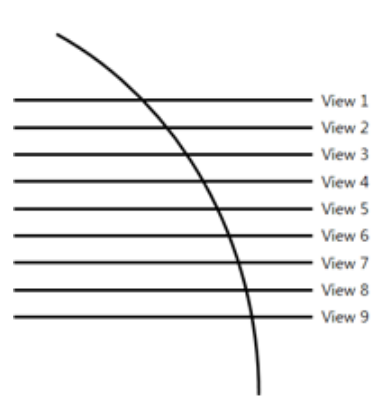

(a)

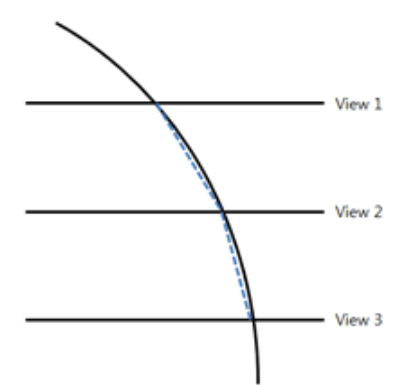

(b)
그림 22. Sinogram (a) 9 개 view (b) 3 개 view

Fig. 22. The sinogram which has (a) 9 views (b) 3 views

\section{IV. 결 론}

의료 영상 분야에서 $\mathrm{CT}$ 촬영의 피폭 방사선량을 줄이는 것은 큰 관심사가 되고 있다. $\mathrm{X}$-선의 출력 을 감소시키는 방법과 view의 수를 줄여 방사선량 을 줄이려는 다양한 연구 내용이 제시되고 있다. 피 폭선량이 큰 고해상도 $\mathrm{CT}$ 이미지와 근사한 화질을 갖기 위해서는 저선량 촬영 시에 발생하는 다양한 종류의 잡음과 그로인한 재구성 영상의 왜곡 문제 가 해결되어야만 한다. 본 논문에서 제시한 방법은 선형보간법에 비해 최대 5\%(180개의 view를 이용 한 경우)의 향상을 보였으며, 제한된 수의 view를 이용하여 영상을 재구성해야 하는 상황에서 왜곡 문제를 해결하는 하나의 기법으로 사용될 수 있을 것으로 생각된다. 추후 연구로서, 높은 출력의 X-선 
view와 낮은 출력의 X-선 view를 상호 보완적으로 이용하여 전체적인 피폭선량은 낮추면서 해상도를 높이는 방식을 고려할 수 있다.

\section{References}

[1] The Korean Society of Medical Imaging Technology, "Textbook of Computed Tomography 2nd edition”, 2005년.

[2] Jianhua Ma, Jing Huang, Zhengrong Liang, Hua Zhang, Yi Fan, Qianjin Feng, Wofan Chen "Image Fusion for Low-Dose Computed Tomography Reconstruction," IEEE, Nuclear Science Symposium and Medical Imaging Conference (NSS/MIC), pp.4239-4243, Oct, 2011.

[3] Tianfang Li, Xiang Li, Yuziang Xing, Holgbing Lu, Kiang Hsieh and Zhengrong Liang, "A strategy for reduction of streak artifacts in low-dose CT," IEEE, Nuclear Science Symposium Conference Record, Vol 4, pp.2743-2747, 2003.

[4] Nevzat Karabulut, Mustafa Törü, Veli Gelebek, Meltem Gülsün, O. Macit Ariyürek, "Comparison of low-dose and standard-dose helical CT in the evaluation of pulmonary nodules" ESTI, Vol.8, No.10, June, 2001.

[5] R. R. Galigekere, K. Wiesent, D. W. Holdsworth, "Techniques to alleviate the effects of view aliasing artifacts in computed tomography" Med. Phys., Vol.26, No.6, June, 2006.

[6] A. Goshtasby, David A. Turner, Laurens V. Ackerman "Matching of Tomographic Slices for Interpolation" IEEE, Transactions on Medical Imaging, Vol.11, No.4, Dec, 2005.

[7] Xiao Han, Erik Pearson, Jungou Bian, Seungryong Cho, Emil Y. Sidky, Charles A. Pelizzari, Xiaochuan Pan "Preliminary Investigation of Dose Allocation in Low-dose Cone-beam CT," IEEE, Nuclear Science Symposium Conference Record (NSS/MIC) pp.2051-2054, Nov, 2010.

[8] Junguo Bian, Xiao Han, Jiong Wang, Emil
Y. Sidky, Lingxiong Shao, Xiaochuan Pan "Low-dose CT in SPECT/CT patient scan," IEEE, Nuclear Science Symposium Conference Record (NSS/MIC), pp.2042-2045, Nov, 2010.

\section{김 재 민 (Jae-Min Kim)}

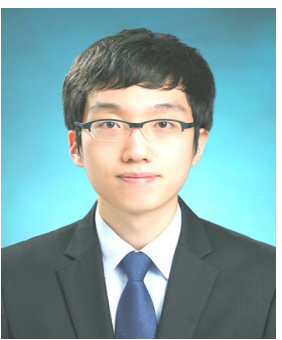

2010년 2월 건국대학교 전자 공학과 졸업

2010년 3월 현재 건국대학교 전자공학과 석사과정

<관심분야> 전자공학, 의료영

상신호처리

이 기 승 (Ki-Seung Lee)

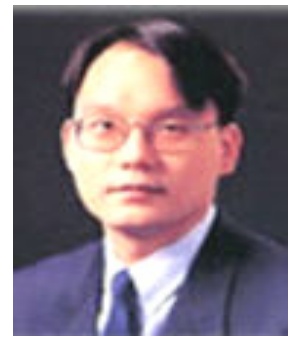

1991년 2월 연세대학교 전자 공학과 졸업

1993년 2월 연세대학교 대학원 전자공학과 석사

1997년 2월 연세대학교 대학원 전자공학과 박사

2001년 9월 현재 건국대학교

정보통신대학 전자공학부 교수

<관심분야> 전자공학, 생체신호처리 